\title{
27. THE MATUYAMA-BRUNHES GEOMAGNETIC REVERSAL FROM TWO DEEP-SEA CORES OF THE EASTERN EQUATORIAL ATLANTIC ${ }^{1}$
}

\author{
Jean-Pierre Valet, ${ }^{2}$ Lisa Tauxe, ${ }^{3}$ and Jan Bloemendal ${ }^{4}$
}

\begin{abstract}
Matuyama-Brunhes geomagnetic polarity transitions recorded in Holes $659 \mathrm{C}$ and $664 \mathrm{D}$, cored with the hydraulic piston corer during Ocean Drilling Program Leg 108, were selected for detailed study. The sections containing the reversals, as identified by shipboard results, were sampled using " $U$ " channels. Few intermediate polarity directions were obtained from Hole $659 \mathrm{C}$; consequently, no interpretation of this record in terms of transitional field behavior was attempted. However, the record from Hole 664D, located at the equator, is characterized by a gradual easterly progression of the declination from reverse to normal polarity and no deviation of the inclination from a mean value of $0^{\circ}$. The field intensity was reduced to about $20 \%$ of its pretransitional value. The absence of inclination changes combined with easterly declinations constrains the Virtual Geomagnetic Pole path to lie along the meridian $90^{\circ}$ to the east. Such behavior does not resemble transitional field models, which neglect nonzonal terms. A comparison of this record with other reliable records shows that the behavior of the geomagnetic field during this reversal cannot be explained by a model involving a simple field geometry.
\end{abstract}

\section{INTRODUCTION}

Detailed paleomagnetic records obtained in the past few years from sedimentary sequences on land and the deep sea have provided important information about the behavior of the geomagnetic field during reversals and have demonstrated that sediments are well suited for this kind of study. Sediments can provide multiple records of the same reversal from widely separated localities; global coverage is necessary to constrain the harmonic content of transitional fields.

The most thoroughly studied reversal is the MatuyamaBrunhes (M-B), for which about a dozen records have been published (Hillhouse and Cox, 1976; Fuller et al., 1979; Niitsuma, 1971; Clement et al., 1982; Clement and Kent, 1984, 1987; Theyer et al., 1985; Valet et al., 1988). However, the field morphology during this transition is still poorly described; most records are characterized by few intermediate directions, and in some cases the primary component of magnetization was not clearly isolated. Moreover, the geographical distribution of the sites is restricted to mid-northern latitudes, whereas equatorial and Southern Hemisphere records are necessary for a better description of the transitional field geometry.

In view of the very short time span (several thousands of years) of reversals, and because postdepositional reorientation of the magnetic grains may increase the time constants involved in the recording processes, accumulation rates of at least $30-40 \mathrm{~m} / \mathrm{m} . \mathrm{y}$. are desired to obtain detailed records of transitions. Unfortunately, most conventional piston cores are not long enough to reach the last reversal in such high sedimentation rate areas. The hydraulic piston corer (HPC) and the advanced hydraulic piston corer (APC) developed by the Deep Sea Drilling Project (DSDP) have recovered long

\footnotetext{
${ }^{1}$ Ruddiman, W., Sarnthein, M., et al., 1989. Proc. ODP, Sci. Results, 108: College Station, TX (Ocean Drilling Program).

2 Centre des Faibles Radioactivités, Laboratoire Mixte CNRS-CEA, Parc du CNRS, B. P. 91198, Gif/Yvette Cedex, France.

3 Scripps Institution of Oceanography, La Jolla, CA 92093.

${ }^{4}$ Graduate School of Oceanography, University of Rhode Island, Narragansett, RI 02882-1197.
}

sequences that allow the determination of detailed records of the magnetostratigraphy and polarity transitions.

Eleven sites were drilled during the north-south transect of Leg 108 along the northwest African margin. Magnetostratigraphic results from these sediments are presented by Tauxe, Valet, and Bloemendal (this vol.). Based on their results, several boundary sections were selected for detailed shorebased studies from Holes $659 \mathrm{C}\left(18^{\circ} 04^{\prime} \mathrm{N}, 21^{\circ} 01^{\prime} \mathrm{W}\right)$ and $664 \mathrm{D}$ $\left(0^{\circ} 06^{\prime} \mathrm{N}, 23^{\circ} 16^{\prime} \mathrm{W}\right)$.

\section{METHODS}

The M-B boundary was identified at $23.3 \mathrm{mbsf}$ (meters below seafloor) in Hole $659 \mathrm{C}$ from the results of the continuous shipboard measurements (Fig. 1, Core 108-659C-3H). The good magneto- and biostratigraphic time control (this vol.) indicates that the sediment accumulated with an average rate of $30 \mathrm{~m} / \mathrm{m} . \mathrm{y}$. over the last $3 \mathrm{~m} . \mathrm{y}$. This value is a little lower than in Hole 664D, where below $15 \mathrm{mbsf}$ the accumulation rate was $51 \mathrm{~m} / \mathrm{m} . y$. The M-B transition here was identified at about 28 mbsf (Fig. 1, Core 108-664D-4H).

The transitional interval at Site $659 \mathrm{C}$ consisted of light gray nannofossil ooze, which was sampled with "U"-channel plastic containers (Tauxe et al., 1983). Two separate 0.5-m-long "U"channel samples were taken from the bottom of Section 108-659C$3 \mathrm{H}-3$ and top of Section 108-659C-3H-4 (between 23 and 24 mbsf). Section 108-664D-4H-5 consisted of dark grey nannofossil ooze. Below 28.4 mbsf the brown sediment changes appear somewhat disturbed. In 664D, the transitional section was sampled with a single "U" channel.

The " $U$ "-channeled sediments were sliced into $0.5-1-\mathrm{cm}$-thick wafers using a cheese-knife frame equipped with a very thin steel wire. Owing to the high natural remanent magnetization (NRM) intensity, two to three specimens per stratigraphic level were obtained from the sediments; all specimens were placed in plastic boxes.

The magnetic mineralogy of the specimens was investigated by stepwise acquisition of the isothermal remanent magnetization (IRM), followed by stepwise alternating-field (AF) demagnetization of the saturation IRM (SIRM). The approximate grain-size ranges of the magnetic grains were determined by using plots of the anhysteretic susceptibility, X(ARM), 0.1-mT direct field, 100-mT AF, vs. low-field susceptibility, X (King et al., 1982). The downcore variations in susceptibility and ARM were scrutinized within the transition zones to check the uniformity of the magnetic properties.

The measurements were made in the shielded room of the Scripps Paleomagnetic Laboratory with a CTF three-axis cryogenic magnetometer. Stepwise AF demagnetization was usually performed in 
$108-659 \mathrm{C}-3$

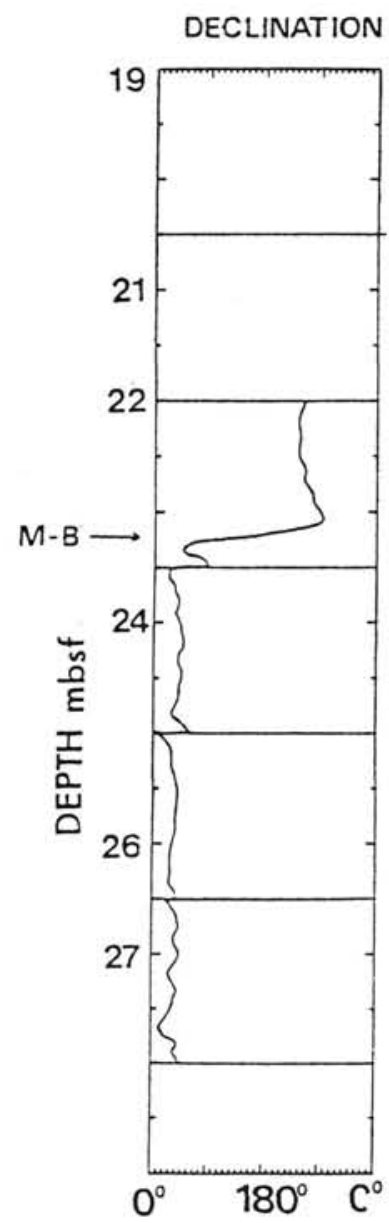

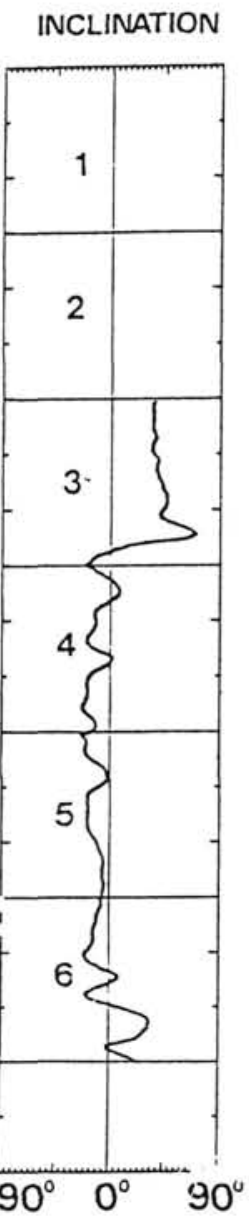
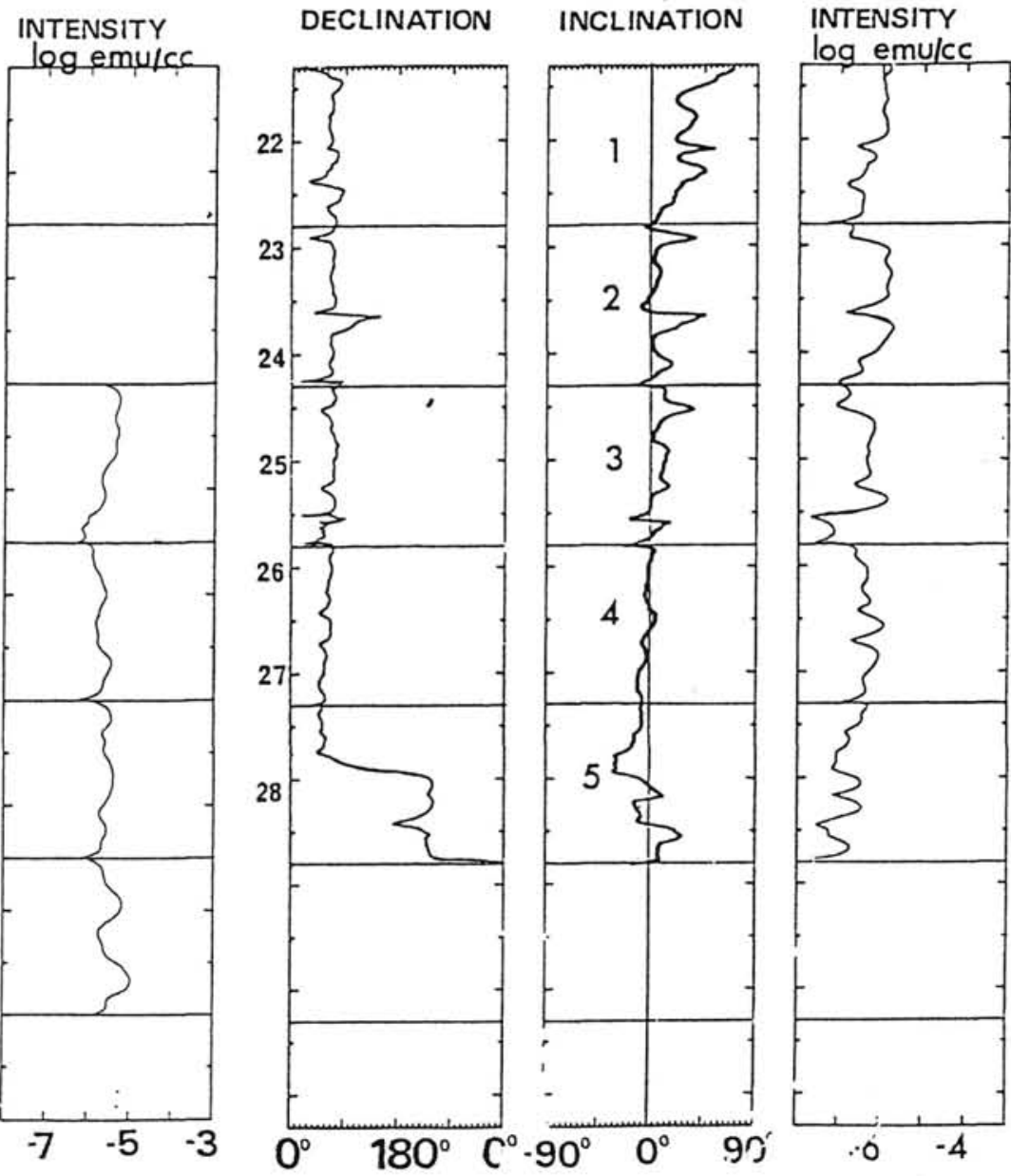

Figure 1. Results of the shipboard measurements of Core 108-659C-3H and Core 108-664D-4H after demagnetization to $5 \mathrm{mT}$.

steps of $2.5-5 \mathrm{mT}$. Beyond $20 \mathrm{mT}$ we used a procedure of double demagnetization when anomalous intensity jumps and/or small erratic directional changes occurred between successive steps. This routine, applied on many samples from Hole $659 \mathrm{C}$, was not necessary for specimens from Hole 664D.

\section{RESULTS}

\section{Hole 659C}

Results from the IRM acquisition experiments indicate that the saturation of the remanence is obtained after 0.25 teslas and is thus consistent with a mineralogy dominated by magnetite. The sudden, large drop in susceptibility and ARM within 23.37 and 23.44 mbsf reflects the absence of finegrained magnetite in this interval. Below $23.4 \mathrm{mbsf}$, the low-field susceptibility, X (Fig. 2), as measured on a Sapphire Instruments SI-1, is lower than the noise level of the instrument, and there is a significant increase in the ARM intensities at these levels. The variations of these two parameters, therefore, strongly suggest changes in the magnetic grain-size distribution toward finer grain sizes.

A total of 111 samples, including all those located near or within the transition interval, were subjected to stepwise AF demagnetization, and 46 samples from Section 108-659C-4H-3 were thermally demagnetized at steps of $40^{\circ}-50^{\circ} \mathrm{C}$ up to $580^{\circ} \mathrm{C}$. We demagnetized 47 samples at 3 levels and the rest of the samples were demagnetized at $20 \mathrm{mT}$; this was done so that at least one specimen per level was stepwise demagnetized. The typical demagnetization diagrams in Figure 3 show the presence of two distinct components. The first, removed by AF demagnetization to $10 \mathrm{mT}$, is characterized by steeply downward inclinations accompanied by little change in declination. Because this component is not directed along the present geomagnetic field, it was not acquired in situ; it could have been acquired during coring or sample storage. After removal of this soft component by demagnetization to $10 \mathrm{mT}$, the characteristic component is isolated and decreases linearly toward the origin; its direction could be determined with precision by hand fitting a straight line through the last 4 or 5 points. Twenty-eight specimens (three located in the transition zone) exhibited complex behavior that did not allow an unambiguous determination of the characteristic direction; hence, these were rejected.

The declination and inclination records obtained from 256 samples are shown in Figure 4. We plot the data as vector means for each stratigraphic level. Because the core was not oriented, the declinations have been corrected by adjusting the mean normal value to $0^{\circ}$. Using the same correction for the entire section, the mean reversed declination is $180^{\circ}$. The mean normal $\left(33^{\circ} \pm 9.8^{\circ}\right)$ and reversed $\left(29.7^{\circ} \pm 7^{\circ}\right)$ inclinations agree with the value of the geocentric dipole field at the site latitude $\left(33^{\circ}\right)$. The reversed and normal directions are therefore antipodal. There is good consistency between directions of samples from a single stratigraphic level, except within the interval 23.37-23.44 mbsf, 

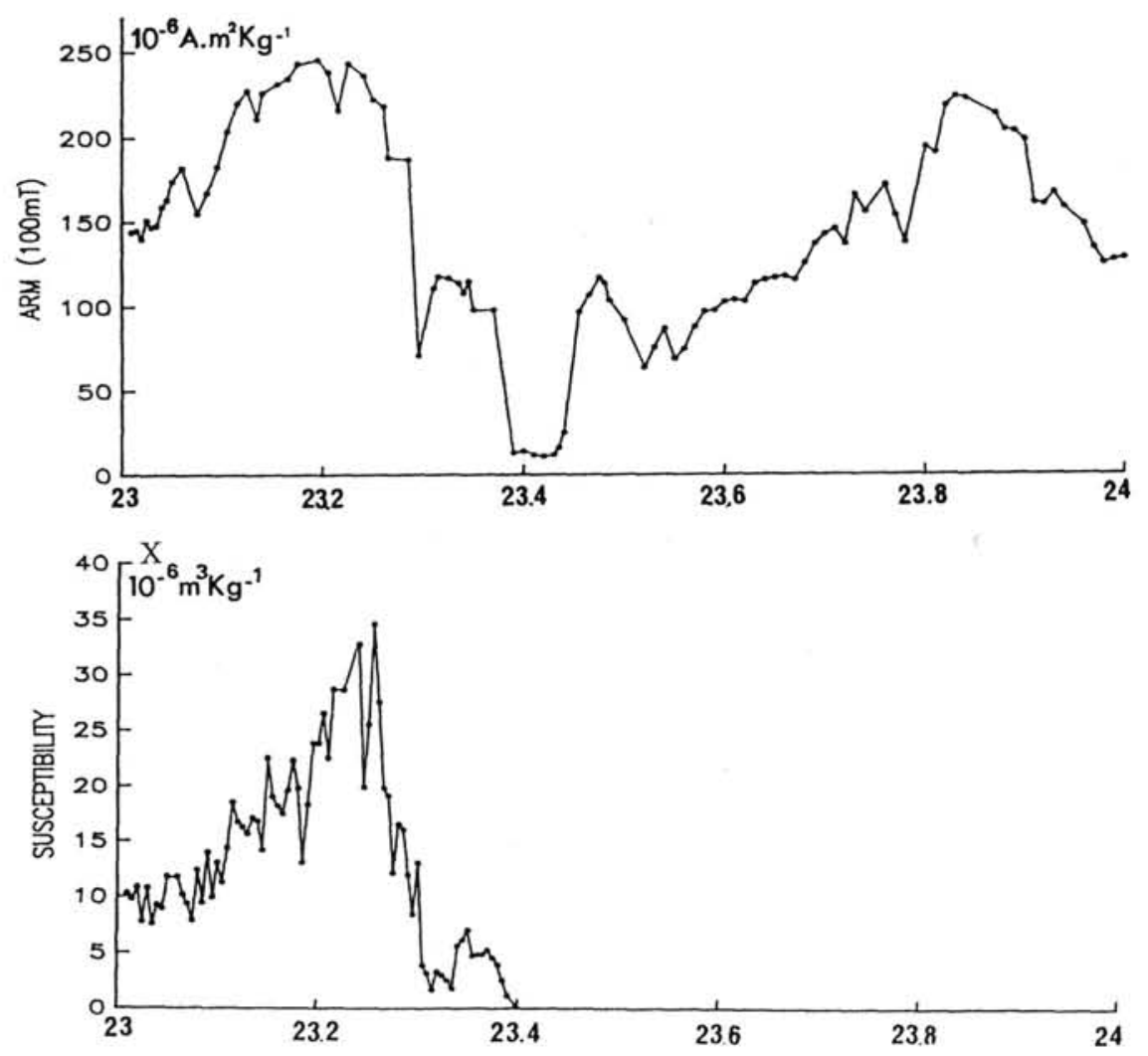

Figure 2. Variations in the ARM (top) and the low-field susceptibility (bottom) of specimens regularly distributed along the sampled interval (Hole 659C). There is a large decrease of both parameters between $23.2-23.43$ mbsf. Below 23.4 mbsf the susceptibility was too low to be measured with accuracy.

where scattered and incoherent directions (hachured zones in Fig. 4) result from the lack of single or pseudosingle domain grains of magnetite. The directions obtained from individual samples show a major discrepancy with the shipboard results plotted in Figure 4. The declination change from reverse to normal values occurs $7.5 \mathrm{~cm}$ higher than the level indicated by the shipboard measurements, and the corresponding inclinations from continuous measurements are characterized by very high positive values. These differences between the data sets are due to the incomplete removal of the secondary component of magnetization by AF demagnetization, which was limited on board by the ODP curatorial staff to $5 \mathrm{mT}$.

Declination and inclination changes do not occur simultaneously. High negative inclinations are observed first, followed by an abrupt declination change from $180^{\circ}$ to $0^{\circ}$. Finally, the inclination moves progressively from negative to positive values. This feature could result from rapid changes in the transitional field and/or from a very low sedimentation rate. However, the transitional interval does not correspond with any visible physical disturbance or apparent discontinuity. Whatever the origin of the lack of intermediate directions, it seems that the time resolution of this record is too low to provide reliable transitional directions. In view of these results and of the large downcore variations of the magnetic parameters, we did not attempt to model the variations of the geomagnetic field intensity during this reversal.

\section{Hole 664D}

Results from stepwise acquisition of IRM (Fig. 5), performed on 15 regularly spaced samples within the section, indicate that total saturation is attained after treatment to 0.25 $\mathrm{mT}$ and that the medium destructive field of the SIRM is 20 $\mathrm{mT}$. These results are consistent with the presence of magnetite as the main carrier of the magnetization.

The AF and thermal demagnetizations performed on pilot samples were equally efficient in isolating the primary component. Because AF demagnetization has the advantage of preserving the samples for other experiments, we prefer this method. A total of 88 samples, including all of those within or in the proximity of the transitional levels, were stepwise demagnetized. The rest of the specimens were demagnetized in three steps. Most of the demagnetization diagrams (Fig. 6) are characterized by the presence of a very soft component that is completely removed after $5 \mathrm{mT}$ or $100^{\circ} \mathrm{C}$. This component has no preferential orientation and was probably acquired during sample storage. The characteristic component could be easily measured even after demagnetization to $60-80$ $\mathrm{mT}$. We rejected 18 samples that did not yield any reliable direction.

The declination and inclination records of the vector means at each stratigraphic level from a total of 220 measured directions are shown in Figure 7. There is good consistency between the directions from identical levels. The inclinations on average are close to $0^{\circ}$, in agreement with the equatorial position of the site. Below 28.4 mbsf anomalously high inclinations occur with a general increase in scatter of the directions. These levels are also characterized by a change in sediment color, and they appear to be physically disturbed. The general trend of both the declination and inclination variations compares quite well with the shipboard results after 
659C-3-3-130

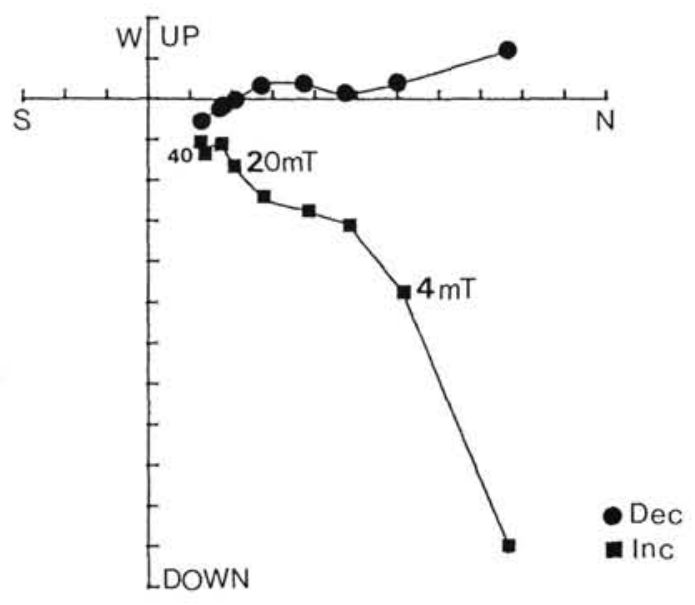

659C-3-4-25

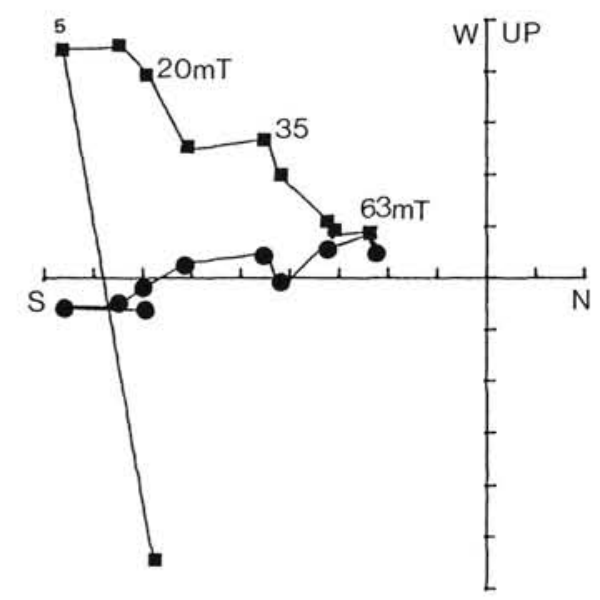

Figure 3. Typical demagnetization diagrams for samples from Hole $659 \mathrm{C}$. Dec $=$ declination (in degrees); Inc $=$ inclination (in degrees).

treatment to $5 \mathrm{mT}$, in agreement with the fact that the soft component in the discrete samples was removed by $5-\mathrm{mT}$ AF peak field. The transition is characterized by intermediate easterly declinations and by no changes in inclination, which remains close to a mean value of $0^{\circ}$.

Variations in NRM intensities may reflect variations in the geomagnetic field intensity, downcore changes in the nature or the amount of the magnetic carriers, or a combination of these factors. Assuming that a depositional remanent magnetization (DRM) is carried by fine-grained magnetite, relative paleointensity estimates can be obtained by normalizing the magnetization intensities with respect to variations in the concentration of magnetic minerals. Following the approach developed by King et al. (1983), we verified that the sediment met the basic requirements for using ARM variations as a suitable parameter: (1) the uniformity of grain sizes of magnetite and (2) the absence of large downcore variations in the concentration of magnetic material. The ARM $(0.1-\mathrm{mT}$ direct field, $100-\mathrm{mT} \mathrm{AF}$ ) variations are quite limited (Fig. 8) except within the intervals $28-28.1$ and $28.15-28.4$ mbsf, where low values of ARM and NRM intensities reflect decreases in the amount of remanent magnetic material.

The NRM $(20 \mathrm{mT}) / \mathrm{ARM}$ plot in Figure 8 represents our best approximation of the field intensity variations. As in most records, the reversal is associated with a significant intensity decrease, and the interval of low intensity lasts longer than the directional changes. The amplitude of the field intensity changes compared with the prereversal and postreversal values does not exceed a factor of 5. There is no apparent asymmetry between the decay and recovery phases.

\section{DISCUSSION}

From the results obtained after demagnetization, we calculated the successive positions of the Virtual Geomagnetic Poles (VGPs). The few "intermediate" directions obtained from Hole $659 \mathrm{C}$ are reflected by the scarcity of transitional VGPs in the Northern Hemisphere (only one position below $45^{\circ}$ of latitude) and the absence of VGPs in the Southern Hemisphere (Fig. 9). The plot of the VGP latitudes as a function of the stratigraphic position (Fig. 10) shows that the transitional interval extends over only $8 \mathrm{~cm}$. In view of these results, interpretation of this record in terms of geomagnetic field variations is hazardous.

The VGP path recorded at Hole 664D is described by eight intermediate positions distributed in both hemispheres (Fig. 9B). The transition spans a stratigraphic thickness of $20 \mathrm{~cm}$ (Fig. 10), which suggests a duration of $4000 \mathrm{yr}$, assuming an accumulation rate of $50 \mathrm{~m} / \mathrm{m} . y$. Despite the lack of detail in the record from Hole $659 \mathrm{C}$, it is striking that the VGP path is similar to the trajectory obtained from Hole 664D.

Any interpretation of the Hole 664D record in terms of transitional field characteristics would require a comparison with other detailed records of the same reversal. The rigorous selection criteria for reliable records suggested by Valet et al. (1988) includes complete stepwise demagnetization of the transitional samples, investigation of the magnetic mineralogy, and a minimum number of four intermediate directions distributed in both hemispheres. If we strictly apply these criteria, only two records, the Tecopa record of Valet et al. (1988) and the record obtained from Hole 664D, emerge from the large number of studies of this reversal. The VGP paths from these two records are constrained within antipodal longitudinal bands (Fig. 11A). The proximity of the Tecopa trajectory to the site longitude is consistent with a transitional field strongly dominated by axisymmetrical components. However, this interpretation cannot account for the VGPs recorded at Hole $664 \mathrm{D}$ that are restricted within a longitudinal band $90^{\circ}$ to the east of the site meridian.

Hole 609B (Clement and Kent, 1987) is at roughly the same longitude as Hole $664 \mathrm{D}$ but much farther north $\left(50^{\circ} \mathrm{N}, 335^{\circ} \mathrm{E}\right)$. Thus, the possibility exists of comparing the characteristics of the M-B transition at the two sites along a latitudinal transect. In the study from Hole 609B, all the samples were demagnetized at three successive steps, so this record can be considered reasonably reliable. A comparison of the records from Holes 609B and 664D shows that westerly declinations were recorded at Hole 609B while easterly declinations are associated with Hole 664D. Consequently, the two records are characterized by antipodal VGP paths located over the Americas (Hole 609B) and Asia (Hole 664D), respectively (Figs. $11 \mathrm{~A}$ and $11 \mathrm{~B}$ ), which are approximately $90^{\circ}$ east and west of the sites, respectively. This configuration is inconsistent with a transitional field geometry dominated by zonal components that would predict similar paths for sites distributed along the same longitude. Thus, the present data cannot be reconciled 


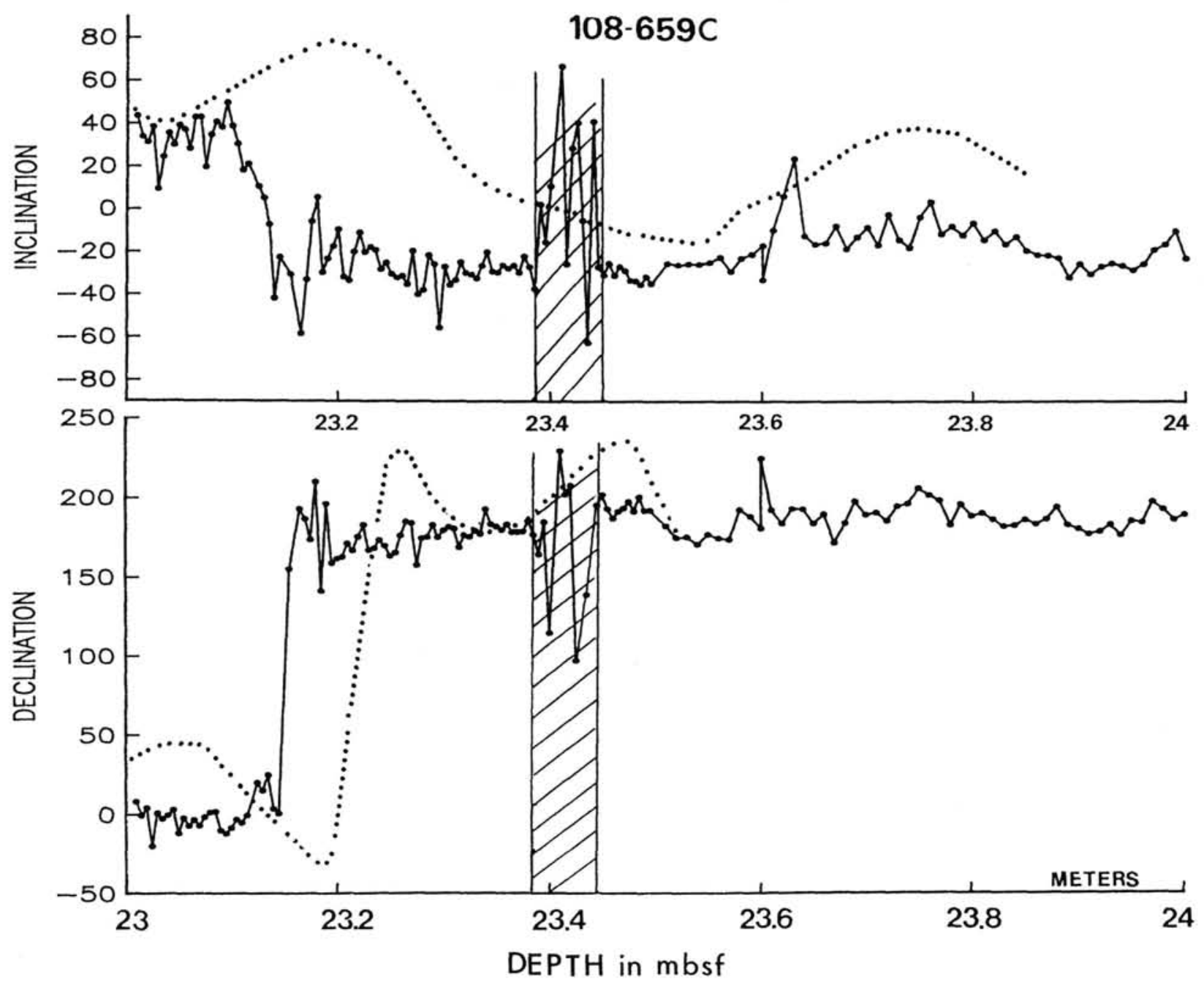

Figure 4. Records of the declination and inclination obtained after AF and thermal stepwise demagnetization compared with the results of the shipboard measurements (shown in dotted lines) obtained after demagnetization to $5 \mathrm{mT}$ only. The directions have been averaged at every level. The scattered directions between 23.37 and 23.44 mbsf have been rejected on the basis of magnetic mineralogy. Declination and inclination given in degrees.
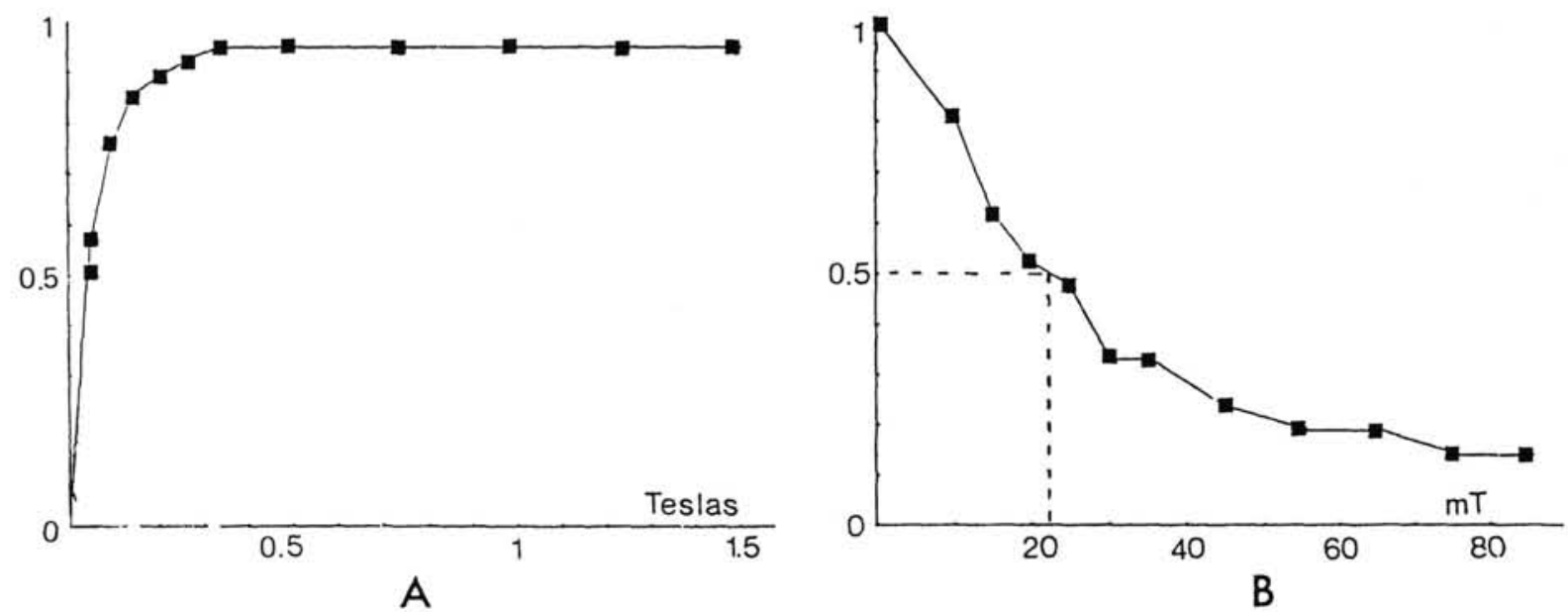

Figure 5. Diagrams showing the acquisition of the IRM (A) and the AF demagnetization of the SIRM (B) of Sample $108-664 \mathrm{D}-4 \mathrm{H}-5,53 \mathrm{~cm}$. The saturation is attained after $0.25 \mathrm{mT}$ and the mean destructive field (MDF) is $20 \mathrm{mT}$. 

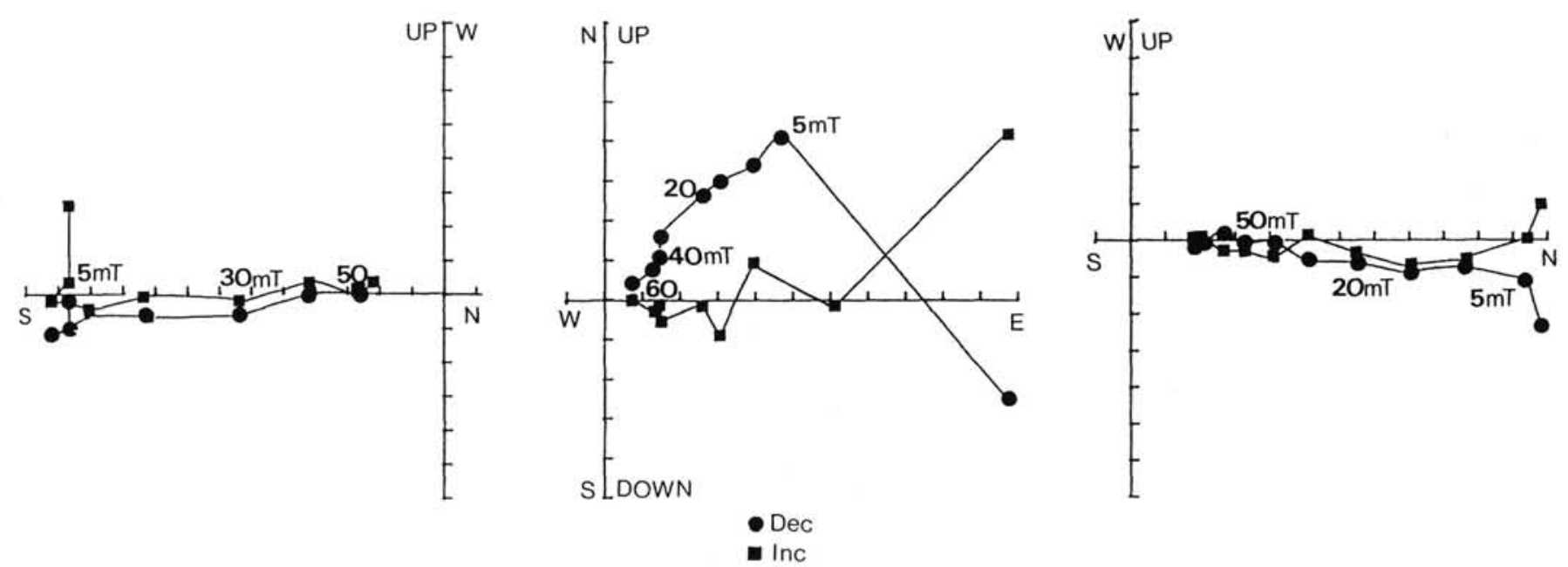

Figure 6. Characteristic demagnetization diagrams for three samples from Section 108-664D-4H-5 with reverse, intermediate, and normal polarities (left to right). $\mathrm{Dec}=$ declination (in degrees); $\mathrm{Inc}=$ inclination (in degrees).

with a simple geometry of the geomagnetic field during this reversal.

A possible explanation for these data is that drifting or standing local sources of the nondipole field dominate during the transitional decay of the main dipole. Based on a frozen flux approximation, which implies that the nondipole secular variation and the dipole field can be treated separately, Le Mouel (1984) recently suggested that the nondipole field cannot disappear during reversals. Some detailed paleomagnetic records seem to be consistent with Le Mouel's suggestion (Valet et al., 1986).

A reduction by only $75 \%$ of the present dipole field intensity allows the dominance of nondipole field features that produce reverse directions locally (Roperch, 1987). The three VGP paths are similar in that they lie along restricted longitudinal zones, while major loops in the VGP trajectories would be expected if drifting components of the nondipole field were dominating the field (Hillhouse and Cox, 1976). This situation would, however, be strongly dependent on the time constants involved in the reversal and on the secular variation (Weeks and Fuller, 1988). Therefore, the present results seem to indicate that the major part of the transition occurred very quickly.

Much more difficult to account for are the antipodal configurations of the Hole 664D and 609B trajectories, which appear to demand harmonics of at least degree 3. Models incorporating both drifting and standing sources could certainly simulate the present data (e.g., by assuming sources located beneath the Pacific and northern Asia). However, these simulations, which are based on only three available records, are not unique and are of little value.

The reliability of these sediments as paleomagnetic recorders of the transitional field variations has been established on the basis of their mineralogic and magnetic properties. Although the results of these experiments are encouraging, we cannot rule out the fact that factors other than field behavior may be responsible for the record, particularly on the very short time scale given (hundreds to thousands of years). Only by obtaining duplicate records from the same geographic areas will it be possible to eliminate and/or estimate the influence of factors independent of the geomagnetic variations.

Another approach might be to compare sedimentary and volcanic records. However, if rapid variations of the nondi- pole field are present during the transition, different features of the field should be observed due to the different time constants involved in the TRM and DRM processes. Our results give new insights on field behavior during the last reversal, and additional records are now crucial to constrain the actual data set even more.

\section{ACKNOWLEDGMENTS}

The authors are pleased to acknowledge A. Mennel for help with measurements, D. R. Clark for technical assistance, and C. Laj and C. Constable for helpful discussions and comments. Brad Clement and an anonymous reviewer made valuable suggestions to the manuscript. Support for this study was provided to J.-P. Valet by NATO, the CNRS ATP OCEANS, and the CEA, and to L. Tauxe by NSF Grant EAR. 8515743 and Texas A\&M \#77348.

\section{REFERENCES}

Clement, B. M., and Kent, D. V., 1984. Latitudinal dependency of geomagnetic polarity transition durations. Nature, 310:488-491.

1987. Geomagnetic polarity transition records from five hydraulic piston core sites in the North Atlantic. In Ruddiman, W. F., Kidd, R. B., Thomas, E., et al., Init. Repts. DSDP, 94, Pt. 2: Washington (U.S. Govt. Printing Office), 831-852.

Clement, B. M., Kent, D. V., and Opdyke, N. D., 1982. BrunhesMatuyama polarity transition in three deep-sea cores. Philos. Trans. R. Soc. London, Ser. A, A306:113-119.

Fuller, M., Williams, I., and Hoffman, K. A., 1979. Paleomagnetic records of geomagnetic reversals and the morphology of the transitional field. Rev. Geophys., 17:172-203.

Hillhouse, J., and Cox, A., 1976. Brunhes-Matuyama polarity transition. Earth Planet. Sci. Lett., 29:51-64.

King, J. W., Banerjee, S. K., Marvin, J., and Ozdemir, O., 1982. A comparison of different methods for determining the relative grain size of magnetite in natural materials: some results for lake sediments. Earth Planet. Sci. Lett., 59:404-419.

King, J. W., Banerjee, S. K., and Marvin, J., 1983. A new rock magnetic approach to selecting sediments for geomagnetic paleointensities studies: application to paleointensity for the last 4000 years. J. Geophys. Res., 88:5911-5921.

LeMouel, J. L., 1984. Outer-core geostrophic flow and secular variation of earth's geomagnetic field. Nature, 311:734-735.

Levi, S., and Banerjee, S. K., 1976. On the possibility of obtaining relative paleointensities from lake sediments. Earth Planet. Sci. Lett., 29:219-226.

Niitsuma, N. D., 1971. Paleomagnetic and paleoenvironmental study of sediments recording Matuyama-Brunhes geomagnetic reversal. Sci. Rep. Tohoku Univ., Ser. 2, 43. 
Roperch, P., 1987. Comportement du champ magnétique terrestre au cours de transitions de polarité [thesis]. Univ. Rennes, France.

Tauxe, L., Labrecque, J. L., Dodson, R., and Fuller, M., 1983. "U" channels-a new technique for paleomagnetic analysis of hydraulic piston cores. Eos, 64:219. (Abstract)

Theyer, F., Herrero-Bervera, E., and Hsü, V., 1985. The zonal harmonic model of polarity transitions: a test using successive reversals. J. Geophys. Res., 90:1963-1982.

Valet, J.-P., Laj, C., and Tucholka, P., 1986. High-resolution sedimentary record of a geomagnetic reversal. Nature, 322:27-32.
Valet, J.-P., Tauxe, L., and Clark, D. V., 1988. The MatuyamaBrunhes transition recorded from Lake Tecopa sediments. Earth Planet. Sci. Lett., 87:463-472.

Williams, I., Weeks, I., and Fuller, M., 1988. A model for transition fields during geomagnetic reversals. Nature, 332:719-720.

Date of initial receipt: 15 February 1988

Date of acceptance: 12 August 1988

Ms 108B-156 

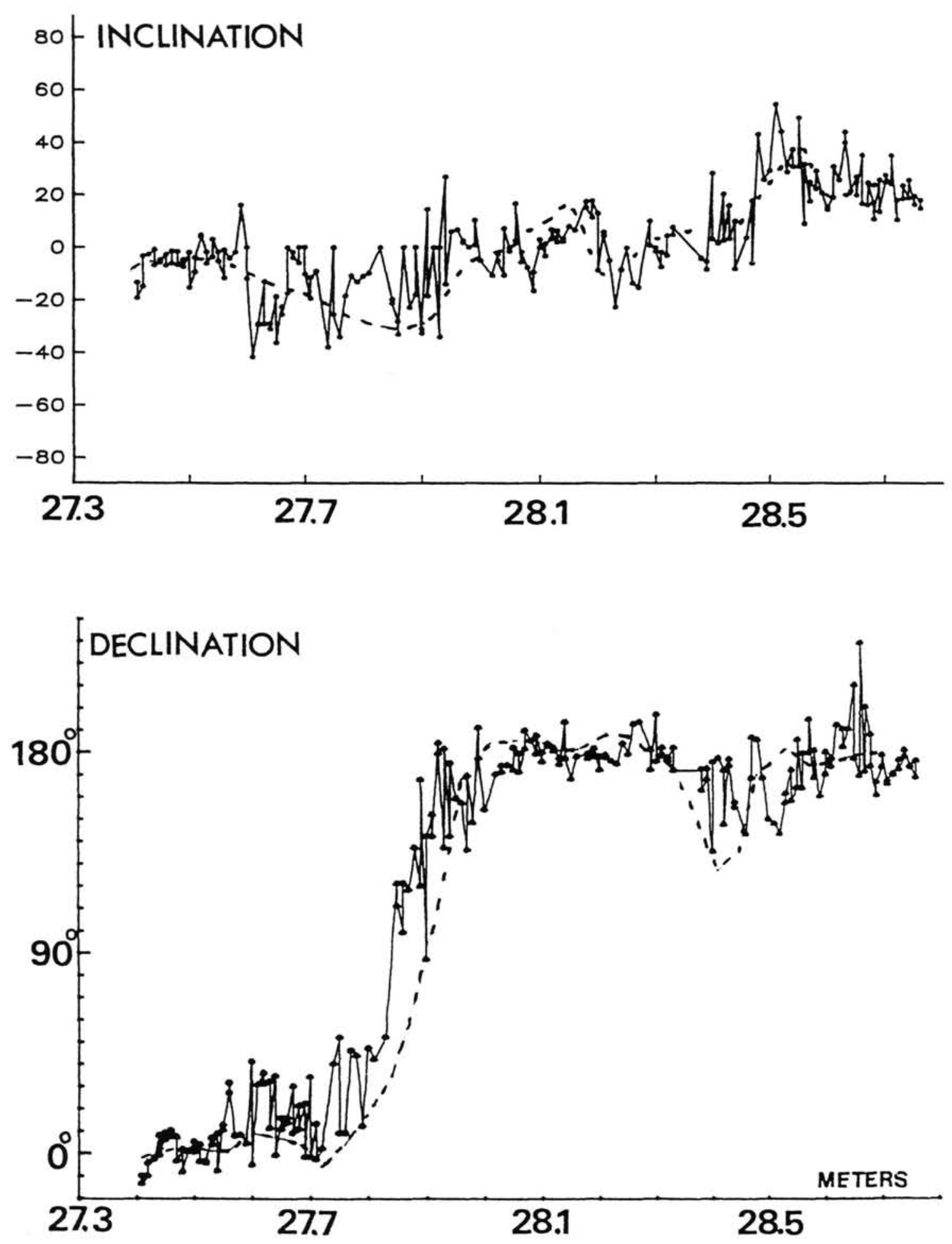

Figure 7. Declination and inclination records (in degrees) of the individual samples compared with the results of the shipboard measurements for samples from Site 664D. There is good agreement between the two data sets. The Matuyama-Brunhes (M-B) transition is characterized by an eastward rotation of the declination and no changes in the inclination. 
MATUYAMA-BRUNHES GEOMAGNETIC REVERSAL
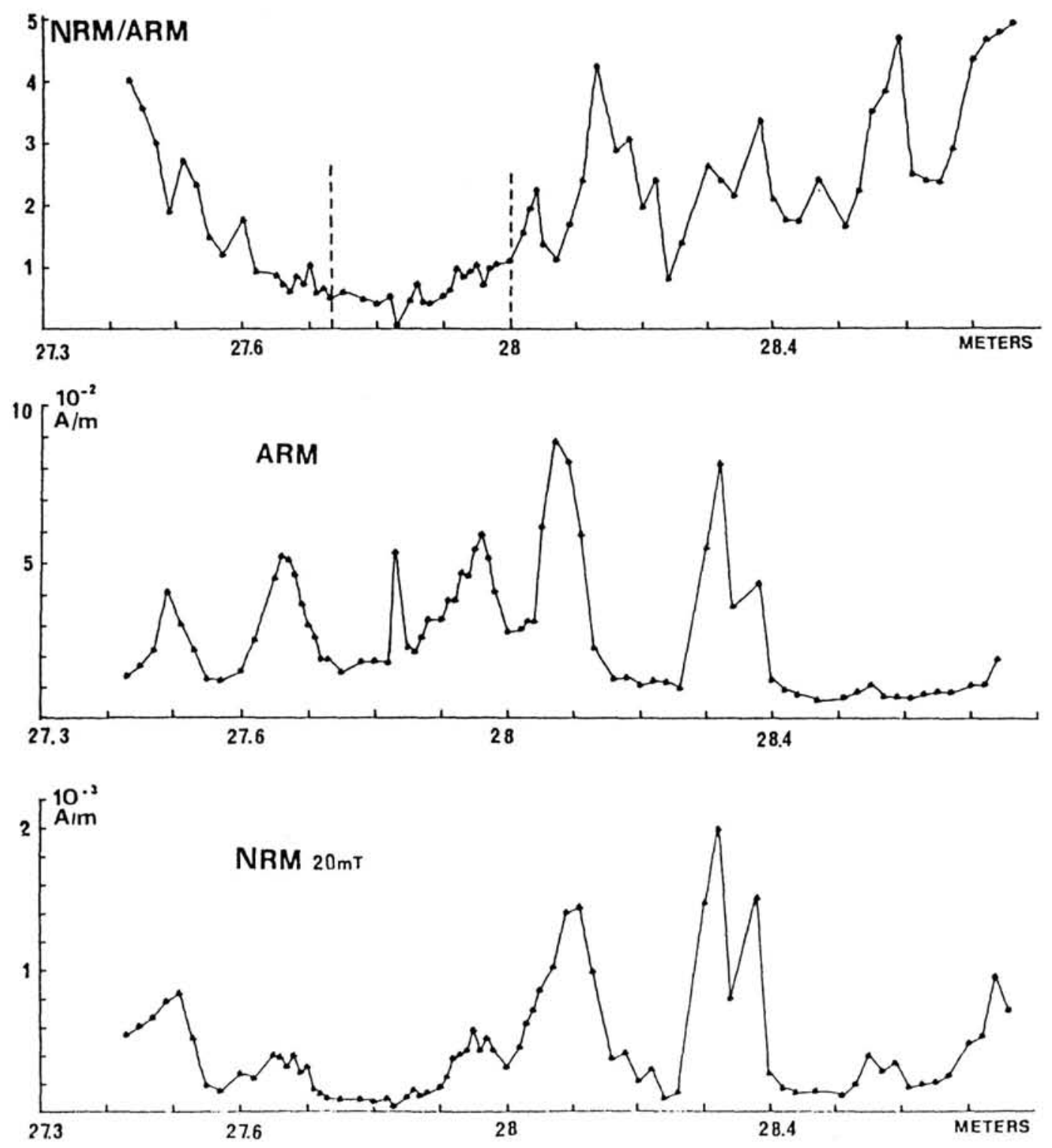

Figure 8. Plots of the NRM (20 mT), ARM $(0.1 \mathrm{mT}, 100 \mathrm{mT})$, and NRM $(20 \mathrm{mT}) / \mathrm{ARM}$ at Site 664D. This plot represents our best estimate of the relative changes in the field intensity.

449 

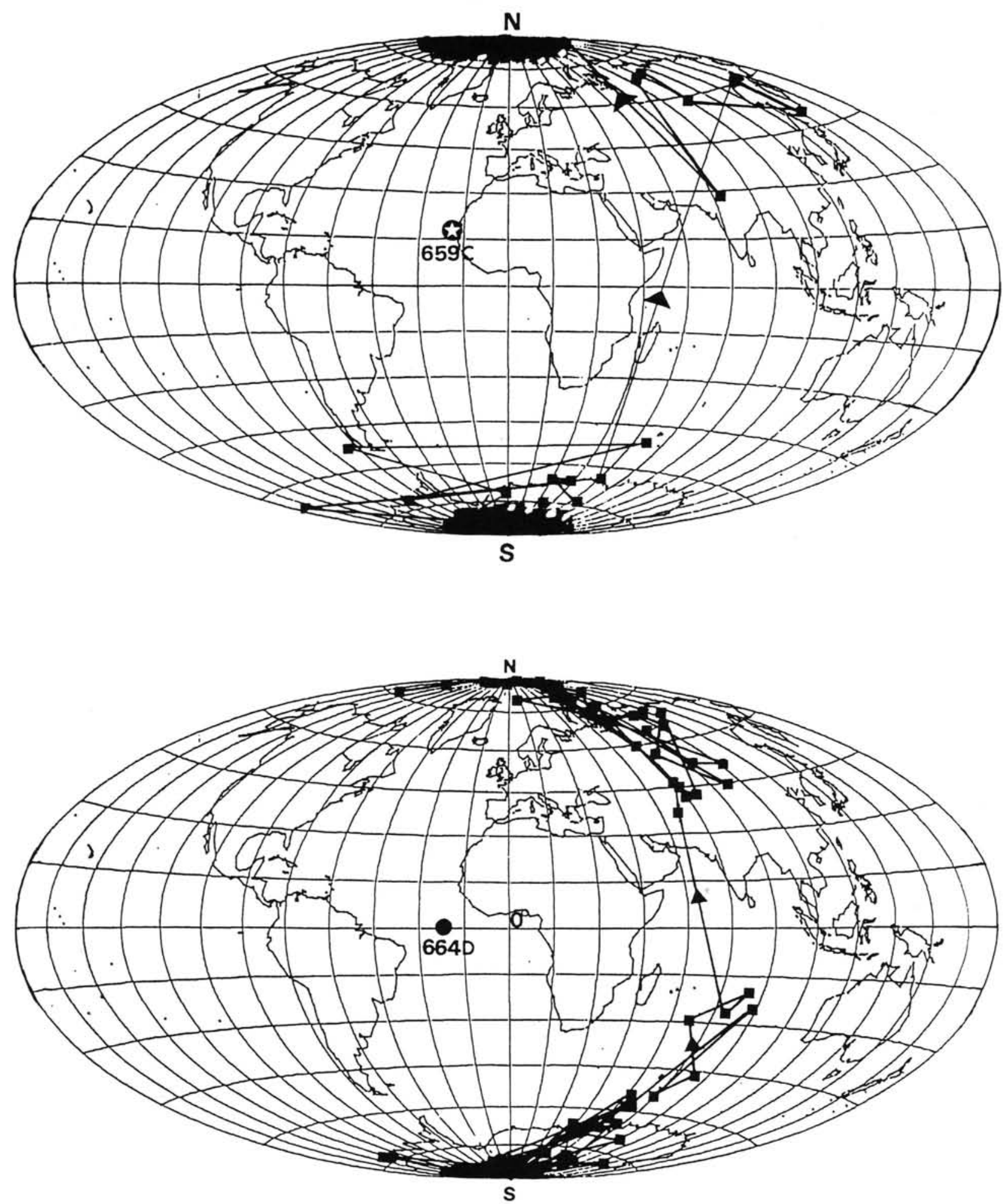

Figure 9. Virtual Geomagnetic Pole (VGP) paths relative to the Matuyama-Brunhes transition recorded from Holes 659C (top) and $664 \mathrm{D}$ (bottom). 

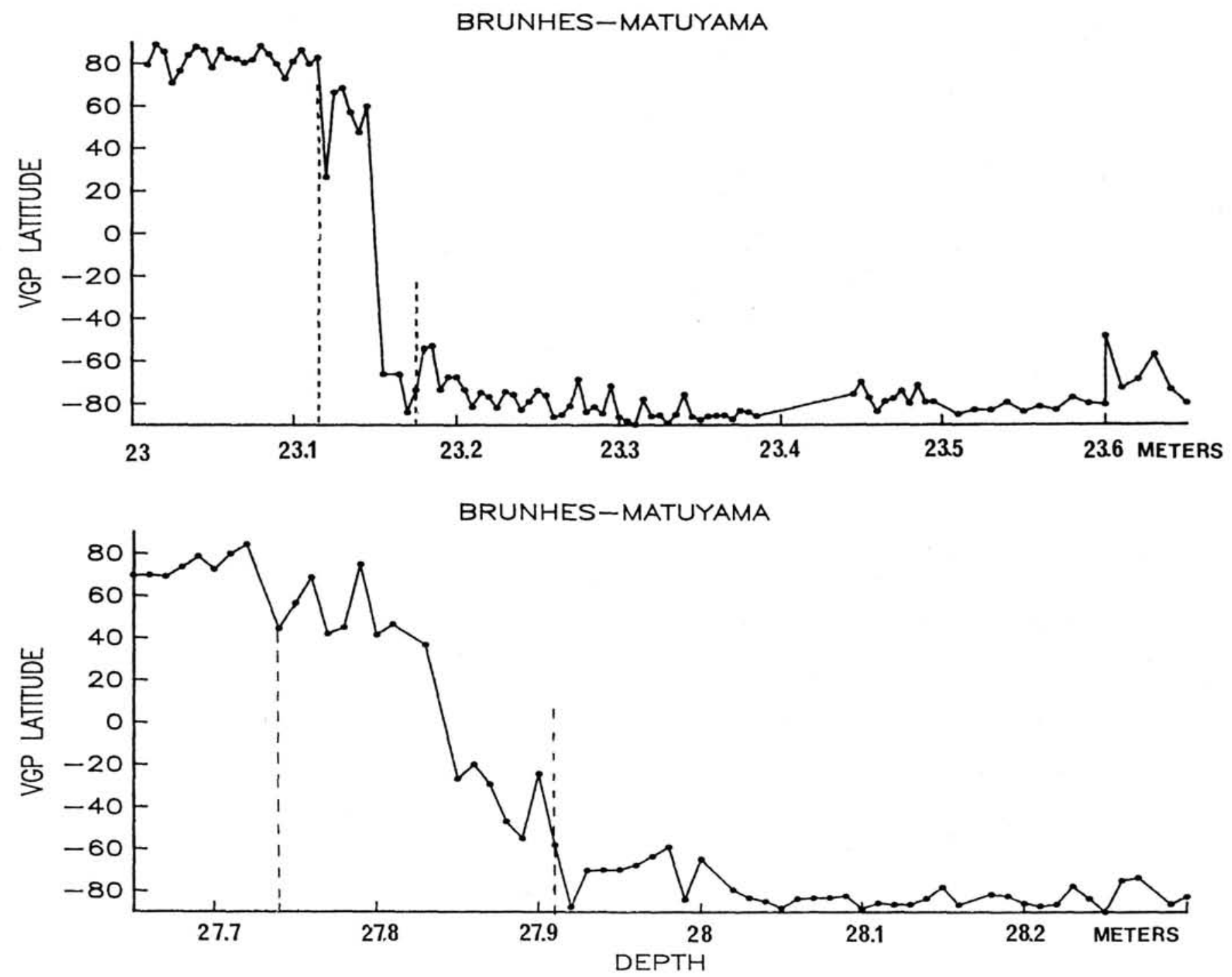

Figure 10. Plots of the VGP latitudes at Sites 659C (top) and 664D (bottom) as a function of sub-bottom depth. Both figures are presented on the same scale in order to compare the length of each transition. 


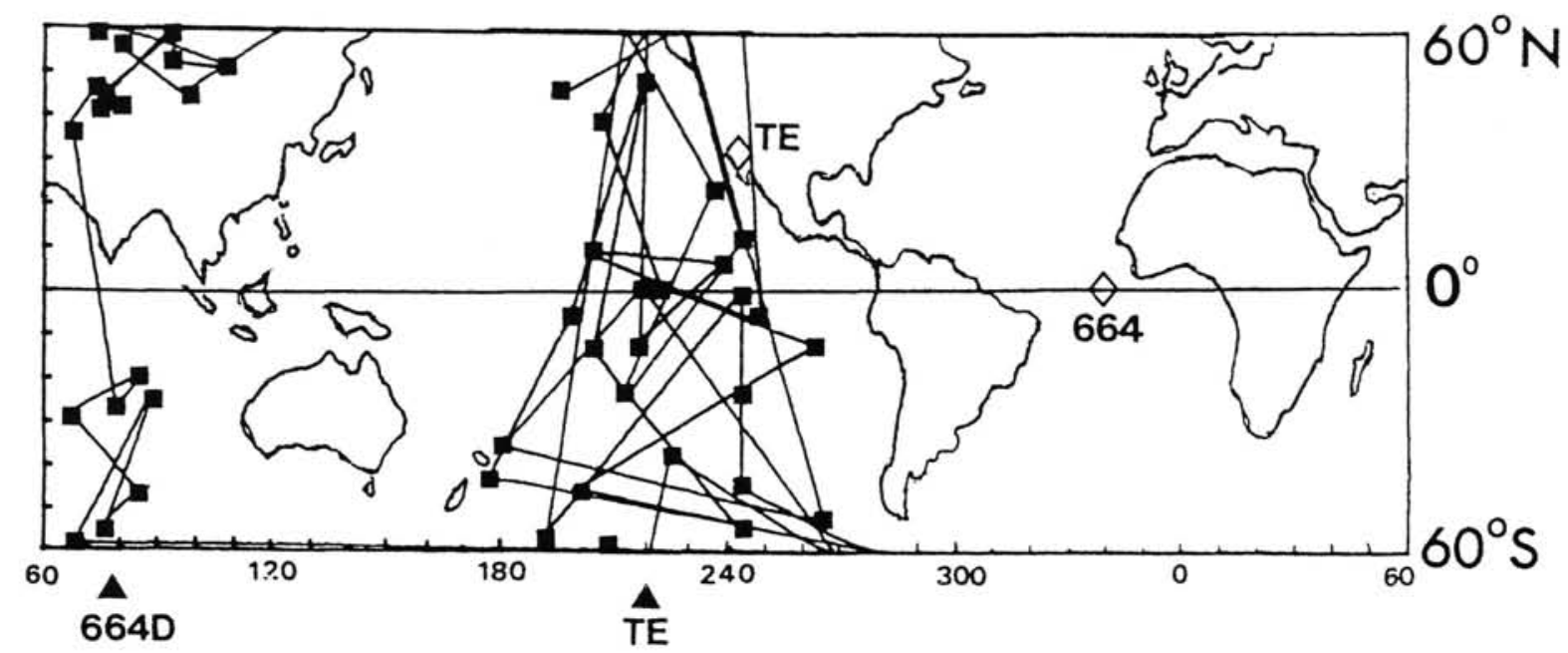

A

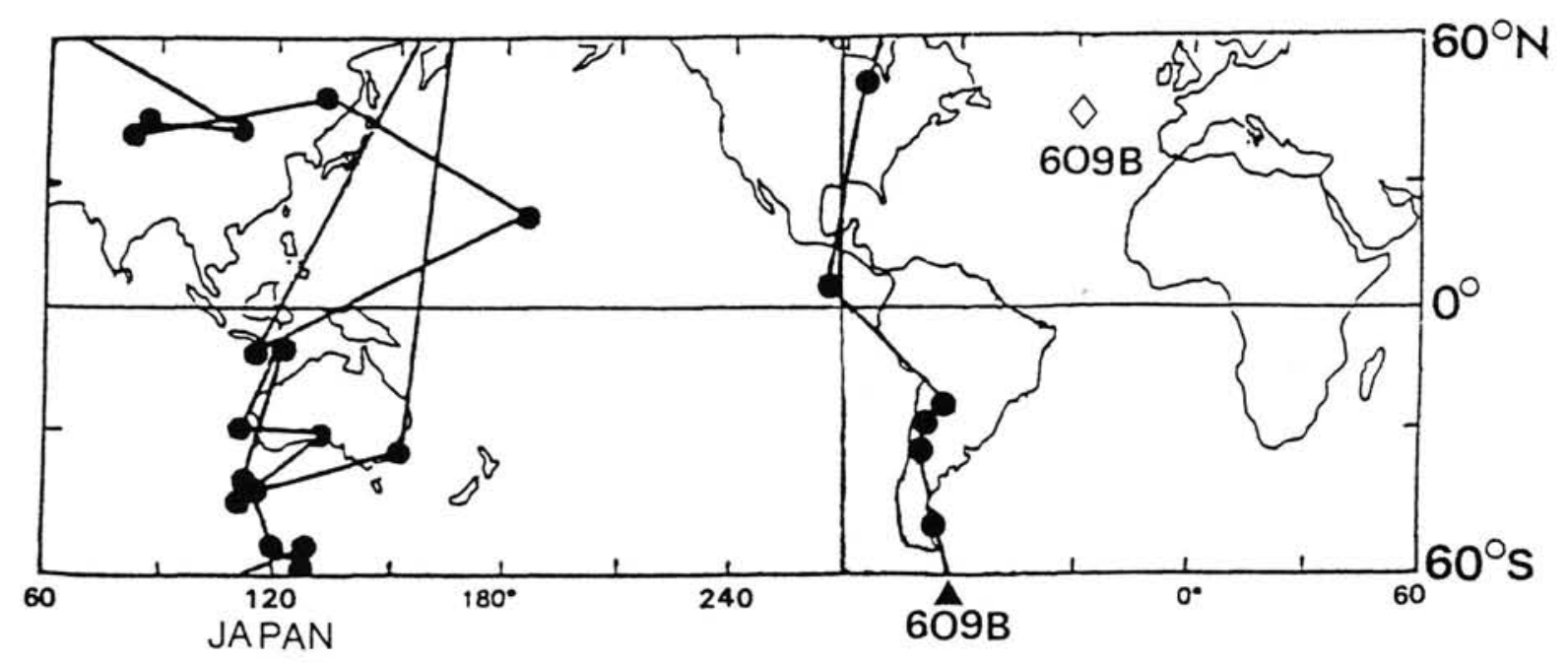

B

Figure 11. A. VGP paths obtained from Hole 664D and from Tecopa, California (Valet et al., 1988), as indicated by the arrows and compared with the site locations. B. VGP path obtained from Hole 609B (Clement and Kent, 1987). For comparison, we have also represented the VGP positions obtained from Japan (Niitsuma, 1971), although this record does not meet the criteria of reliability. 